\title{
TRATAMENTO EM SAÚDE MENTAL NO MODELO MANICOMIAL (1960 A 2000): HISTÓRIAS NARRADAS POR PROFISSIONAIS DE ENFERMAGEM
}

\author{
Andréa Noeremberg Guimarães ${ }^{1}$, Letícia de Oliveira Borba², Liliana Muller Laroccaํ, Mariluci Alves Maftum
}

\footnotetext{
${ }^{1}$ Mestre em enfermagem. Professora Assistente do Departamento de Enfermagem da Universidade do Estado de Santa Catarina. Santa Catarina, Brasil. E-mail: deia_ng@yahoo.com.br

${ }^{2}$ Doutoranda em enfermagem pelo Programa de Pós-Graduação em Enfermagem (PPGEnf) da Universidade Federal do Paraná (UFPR). Enfermeira do Hospital das Clínicas da UFPR. Paraná, Brasil. E-mail: leticia_ufpr@yahoo.com.br

${ }^{3}$ Doutora em enfermagem. Docente do Departamento de Enfermagem (DEnf) e do PPGEnf/UFPR. Paraná, Brasil. E-mail: liliana@ufpr.br

${ }^{4}$ Doutora em enfermagem. Docente Adjunto do DEnf/UFPR. Paraná, Brasil. E-mail: maftum@ufpr.br
}

\begin{abstract}
RESUMO: História oral temática, desenvolvida de 2010 a 2011. Objetivou descrever a vivência de profissionais de enfermagem no tratamento ao portador de transtorno mental no modelo manicomial (1960-2000). Os dados foram coletados mediante entrevista semiestruturada realizada com dois enfermeiros e quatro auxiliares de enfermagem, num hospital psiquiátrico do Paraná. Os dados foram analisados e apresentados em categorias de acordo com a proposta de análise temática. Os colaboradores relataram como tratamentos dispensados ao portador de transtorno mental, terapia medicamentosa, choque cardiazólico, insulinoterapia, eletroconvulsoterapia, entendida como importante recurso para controle da agitação, uso de cubículos e celas fortes como prática comum nos hospitais psiquiátricos, praxiterapia como ocupação. Discorreram, ainda, sobre lençol de contenção, camisa de força, e contenção no leito por faixas de tecido de algodão. Embora muitos destes tratamentos estejam em desuso e sejam criticados, eram os disponíveis e utilizados no período estudado.
\end{abstract}

DESCRITORES: Enfermagem. Enfermagem psiquiátrica. Saúde mental. Tratamento. História da enfermagem.

\section{MENTAL HEALTH TREATMENT ACCORDING TO THE ASYLUM MODEL (1960 TO 2000): NURSING PROFESSIONALS' STATEMENTS}

\begin{abstract}
Thematic oral stories developed from 2010 to 2011. The purpose was to describe the nursing professionals' experience in the treatment of patients with mental disorders according to the asylum model (1960-2000). The data were collected through semi-structured interviews, carried out by two baccalaureate nurses and four nursing assistants in a psychiatric hospital in the state of Parana. Data were analyzed and presented in categories in accordance with the proposal of thematic analysis. The staff reported the following types of treatment delivered to patients with mental disorders: drug therapy, cardiazol shock, insulin therapy, electroconvulsive therapy - seen as an important resource to control agitation - use of cubicles and strong cells as common practices in psychiatric wards, and praxis physical therapy as occupation. They also made reference to bed sheet restraint, straightjackets and bed restraint using cotton bandages Although many of these treatments are now discontinued and criticized, they were available and used during the studied period.
\end{abstract}

DESCRIPTORS: Nursing. Psychiatric nursing. Mental health. Treatment. History of nursing.

\section{TRATAMIENTO EN SALUD MENTAL EN EL MODELO DE MANICOMIO (1960 A 2000): HISTÓRIAS NARRADAS POR PROFESIONALES DE ENFERMERÍA}

\begin{abstract}
RESUMEN: Historia oral temática desarrollada de 2010 a 2011. El objetivo fue describir la vivencia de profesionales de enfermería en el tratamiento al portador de trastorno mental en el modelo de manicomio (1960-2000). Los datos fueron colectados mediante entrevista semi estructurada realizada con dos enfermeros y cuatro auxiliares de enfermería, en un hospital psiquiátrico del Paraná. Los datos fueron analizados y presentados en categorías de acuerdo con la propuesta de análisis temática. Los colaboradores relataron como tratamientos dados al portador de transtorno mental, terapia medicamentosa, choque cardiozólico, insulinoterapia, electroconvulsoterapia, entendida como un recurso importante para el control de la agitación, uso de cubículos y celas fuertes como práctica común en los hospitales psiquiátricos, praxiterapia como ocupación. También discutieron sobre sábana de contención, camisa de fuerza, y contención en el lecho con fajas de algodón. Aunque muchos de estos tratamientos estén fuera de uso y sean criticados, eran los que estaban disponibles y eran utilizados en el periodo estudiado.
\end{abstract}

DESCRIPTORES: Enfermería. Enfermería psiquiátrica. Salud mental. Tratamiento. Historia de la enfermería. 


\section{INTRODUÇÃO}

Por meio do Decreto n. 82/1841 foi fundado no Rio de Janeiro o Hospício Dom Pedro II, inaugurado em 1852, e renomeado mais tarde Hospício Nacional de Alienados. Assim, o Brasil se tornou o primeiro país da América Latina a fundar um grande manicômio com base no alienismo francês, o qual manteve a tradição asilar de abrigar desviantes de todos os tipos, regidos sob a égide das mais diversas intervenções e arbitrariedades. ${ }^{1-3}$

A partir desse evento, foram construídos em todo o país vários asilos e manicômios. Portanto, ao longo dos anos, a assistência psiquiátrica esteve atrelada ao tratamento restrito ao interior dos grandes hospícios, com internação prolongada e manutenção da segregação do portador de transtorno mental do espaço familiar e social. $O$ foco de atenção não era a pessoa, mas a doença. Os portadores de transtorno mental eram marginalizados e desprovidos de autonomia, não sendo vistos como indivíduos ativos na sua terapêutica. ${ }^{4}$

À instituição hospitalar cabia a responsabilidade de eliminar os sintomas da desordem psíquica. Para o tratamento utilizavam recursos que iam desde a internação, técnicas de hidroterapia, administração excessiva de medicamentos, até aplicação de estímulos elétricos ou o uso de procedimentos cirúrgicos. O objetivo das instituições psiquiátricas era utilizar dispositivos que caminhassem na direção da correção do que sinalizava "anormalidade" .5

Foi no interior do manicômio, que surgiu a enfermagem brasileira. Sua origem não objetivou melhorar a assistência aos internos, mas vigiar, controlar e puni-los por seus atos. Não existiam trocas sociais entre trabalhadores de saúde e os internos, como comunicação, afetividade e acolhimento, ${ }^{6}$ os portadores de transtorno mental não recebiam tratamento digno, muitas vezes eram tratados com violência e, por não serem estimulados, suas potencialidades eram reduzidas até se tornarem incapazes de regressar ao convívio social. ${ }^{4}$

Há que se considerar que, desde aproximadamente 1978, o modelo de atenção em saúde mental no Brasil vem sofrendo um redirecionamento influenciado pelo Movimento da Reforma Psiquiátrica que preconiza a criação de novos dispositivos de tratamento de base comunitária como os Centros de Atenção Psicossocial e mudanças na terapêutica e no modo de conceber e tratar a pessoa com transtorno mental. Entretanto, para que práticas adotadas no passado, não se repitam pelo desconhecimento em tempos de reformulação da assistência nesta área do conhecimento, faz-se necessário manter o registro de tais práticas por meio das memórias.

O recorte temporal de 1960-2000 para esta pesquisa se justifica pela possibilidade de encontrar profissionais de enfermagem que tivessem vivenciado sua prática profissional anterior a 2001, quando efetivamente se estabelece um aparato legal para a reformulação da assistência psiquiátrica no país. Desse modo, nesta pesquisa tem-se por objetivo: descrever a vivência de profissionais de enfermagem no tratamento ao portador de transtorno mental no modelo manicomial (1960-2000).

\section{MÉTODO}

Trata-se de uma pesquisa qualitativa, com abordagem da história oral temática, desenvolvida de fevereiro de 2010 a março de 2011, em um hospital psiquiátrico no Paraná, com seis colaboradores (dois enfermeiros e quatro auxiliares de enfermagem).

No que se refere ao número de colaboradores entrevistados, a história oral normalmente tem sido explorada em seu aspecto mais diminuto, devido às dificuldades de trabalhar com elevada quantidade de material. ${ }^{7}$ Portanto, devido à quantidade de material oriundo das narrativas, optou-se por encerrar as entrevistas em seis colaboradores.

Os critérios de inclusão foram: ser maior de dezoito anos e ter desenvolvido sua prática profissional em uma instituição asilar no período de 1960 a 2000.

Os dados foram obtidos mediante entrevista semiestruturada, gravada e transcrita, com a questão: Relate os modos de tratamento ao portador de transtorno mental que você vivenciou na prática de enfermagem anteriormente às mudanças decorrentes da reforma psiquiátrica.

A pesquisa foi aprovada pelo Comitê de Ética em Pesquisa do Setor de Ciências da Saúde da Universidade Federal do Paraná (CAAE 4187.0.000.091-09), em consonância com a Resolução 196/96 do Conselho Nacional de Saúde. ${ }^{8}$

As narrativas foram analisadas e apresentadas em categorias de acordo com a proposta de análise temática ${ }^{9}$ que inclui a fase de ordenação, classificação e análise final dos dados.

A fase de Ordenação dos dados incluiu a transcrição de fitas cassetes; releitura do material; 
organização dos relatos e dos dados de observação. Assim, nesta fase foi realizada a transposição do oral para o escrito segundo envolvendo três fases: transcrição, textualização e transcriação.?

Na fase Classificação dos dados fez-se leitura exaustiva dos textos originados da transcriação das entrevistas, a qual permitiu apreender a relevância entre as falas, as ideias centrais e organizá-las em categorias temáticas.

$\mathrm{Na}$ fase de Análise final os dados foram organizados em oito categorias temáticas de acordo com a vivência de modos de tratamento narrados pelos colaboradores: medicamentos, choque cardiazólico, insulinoterapia (choque insulínico), eletroconvulsoterapia, cubículo ou cela forte, praxiterapia, lençol de contenção e camisa de força, e contenção no leito por faixas de tecido de algodão.

\section{RESULTADOS E DISCUSSÃO}

Os colaboradores narraram a vivência de diversos modos de tratamentos dispensados à pessoa com transtorno mental, na sequência, são descritas partes de suas narrativas cotejadas com literatura pertinente.

\section{Medicamentos}

As narrativas evidenciaram que até 1960 existiam poucos fármacos para o tratamento psiquiátrico e os disponíveis tinham potencial de ação insuficiente para minimizar os sintomas decorrentes do transtorno mental. Para diminuir a agitação dos pacientes, utilizavam-se medicamentos de forma excessiva, comumente associados a outros tipos de tratamentos.

A medicação era pouca, quase não tinha e a que existia era fraca. Usávamos Haldol de 1 mg e Amplictil de $25 \mathrm{mg}$, mais tarde que chegaram os novos fármacos como o Neozine e o Amplictil de $100 \mathrm{mg}$. Para os casos em que o paciente estava muito agitado, tínhamos também o Sonifen. Administrávamos $1 \mathrm{ml}$ na veia e em cinco minutos a pessoa estava dormindo. Depois entrou o Amplictil aplicado com o Fenergan. A dose de cada medicação era prescrita conforme a agitação do paciente, quando o paciente estava muito agitado e agressivo, eram prescritos três Amplictil e um Fenergan (C6).

A psicofarmacologia teve início em 1952, quando os pesquisadores franceses Jean Delay e Pierre G. Deniker obtiveram sucesso no tratamento das pessoas com transtornos mentais com uma nova substância, a clorpromazina. Eles identifi- caram que ela reduzia a agitação psicomotora, as alucinações e os delírios. Essa ação foi denominada de neurolepsia, e os novos medicamentos com esse emprego passaram a ser chamados neurolépticos. ${ }^{10}$

Assim, a partir de 1952, psicofármarcos como clorpromazina (Amplictil ${ }^{\circledR}$ ), levomepromazina $\left(\mathrm{Neozine}^{\circledR}\right)$ e haloperidol $\left(\mathrm{Haldol}^{\circledR}\right)$, passaram a ser empregados vastamente no tratamento dos portadores de transtorno mental, como uma terapia coadjuvante. ${ }^{11}$ Com o surgimento e, posteriormente, com o aumento na quantidade e qualidade dos psicofármacos, houve uma diminuição da manifestação dos sintomas decorrentes dos transtornos mentais.

Tem-se o reconhecimento da importância do emprego da terapia medicamentosa no tratamento do portador de transtorno mental, porém, atualmente, com o modelo psicossocial vigente, diferentemente do modelo manicomial, enfatiza-se o uso racional do medicamento em associação a outras abordagens terapêuticas como consultas, oficinas terapêuticas, atividades socioterápicas, grupos operativos, psicoterapia e atividades comunitárias, visando a reinserção social do portador de transtorno mental. ${ }^{12-13}$

\section{Choque cardiazólico}

O colaborador C6 narrou que vivenciou até o final da década de 1960, a aplicação do medicamento cardiazol, no tratamento de pessoas com transtornos mentais; narrou como a enfermagem se inseria nessa modalidade de tratamento e externou sua posição em relação aos resultados positivos dessa prática na diminuição da agitação de alguns pacientes em contraposição à medicação oral disponível naquela época.

Utilizávamos em pacientes muito crônicos, surtia quase o mesmo efeito do eletrochoque. O cardiazol era um medicamento que vinha em uma ampola de $1 \mathrm{ml}$. O médico fazia a prescrição, antes de administrá-lo fazíamos os procedimentos preparatórios, como no eletrochoque. O cardiazol era administrado bem rápido via endovenosa, o paciente entrava em convulsão. Essa terapia dava resultado. Nos casos de pacientes superagitados, era uma beleza, pois a medicação oral não surtia efeito (C6).

Terapias convulsivas para tratar pessoas com transtornos mentais graves remontam ao século XVI, quando o médico suíço Paracelsus relatou administrar cânfora via oral para indução de convulsões e tratamento da loucura. Essa informação, em grande parte, foi esquecida, até que em 1934 
o neuropsiquiatra húngaro Ladislas von Meduna começou o seu trabalho com a terapia convulsi$\mathrm{va}^{14}$ desenvolvendo, inicialmente, o tratamento convulsivo induzido por cânfora intramuscular e, posteriormente, pelo cardiazol intravenoso. ${ }^{15}$

As convulsões ocasionadas pelo cardiazol ocorriam rápida e violentamente e eram difíceis de controlar. Às vezes, eram tão severas que causavam fraturas espinhais nos pacientes. Com a chegada de outros métodos para tratar pessoas com transtornos mentais, como os neurolépticos e a eletroconvulsoterapia, o cardiazol foi gradualmente descontinuado no final dos anos 40 e não mais utilizado. Hoje, sua importância é unicamente histórica. ${ }^{15}$

\section{Insulinoterapia (choque insulínico)}

O uso da insulinoterapia foi referido por dois colaboradores. Entretanto, somente o colaborador C6 a vivenciou e detalhou minuciosamente a atuação da enfermagem na aplicação dessa técnica, que, conforme seu relato foi utilizada até o início de 1970.

Aplicávamos 10 unidades de insulina subcutânea às cinco horas da manhã e somávamos 10 unidades a cada dia até que a pessoa fazia o pré-coma. No dia seguinte ao pré-coma, aumentávamos mais 10 unidades de insulina e o paciente entrava em coma. A partir daí, a dose era sempre a mesma, se o paciente fez, por exemplo, coma com 100 unidades de insulina, ele ia tomar sempre essa dosagem até terminar o tratamento. Se o médico tivesse prescrito 30 comas, marcávamos o dia em que ele fez o primeiro coma, contávamos 30 comas e encerrávamos o tratamento. Era comum o médico prescrever 30 comas de insulina e o eletrochoque em coma. Logo que o paciente entrava em coma, injetávamos 20 $\mathrm{ml}$ de glicose endovenosa, ele ia acordando. Em seguida, o levantávamos e mandávamos tomar uma solução de água e açúcar que estava preparada. Geralmente o paciente estava transpirando. Era encaminhado para o chuveiro, tomava banho, trocava de roupa, tomava café bem doce, comia de dois a três pães. Depois, sentava no pátio e andava um pouco (C6).

A terapia por choque insulínico foi descoberta pelo neuropsiquiatra polonês Manfred Sakel e, comunicada, oficialmente em 1933. A introdução da insulinoterapia na psiquiatria se deu quando Sakel, ao causar convulsões com uma dose excessiva de insulina, descobriu acidentalmente que esse tratamento era eficaz para pacientes com psicoses, como a esquizofrenia. ${ }^{15}$

Consistia no uso de doses cada vez mais altas de insulina intramuscular até que o paciente ficasse comatoso. A princípio, esse quadro era revertido com glucagônio após 15 minutos, porém, foram realizadas tentativas de elevar os comas subsequentes até uma hora. Por vezes, eram necessárias mais de 60 aplicações para se observar os resultados. ${ }^{14}$

Em conformidade com os achados de Sakel, mais de $70 \%$ de seus pacientes melhoraram após a realização da terapia por choque insulínico. O desuso desse procedimento se acelerou ao surgirem pesquisas que mostraram que a cura real não era alcançada e que as melhoras na maioria das vezes eram temporárias. ${ }^{15}$

\section{Eletroconvulsoterapia (ECT)}

A história contada pelos colaboradores demonstrou que, até meados da década de 1970, a ECT foi amplamente empregada dentro dos hospitais psiquiátricos. Esse tratamento foi visto como um procedimento importante para a época, pois era um dos poucos recursos disponíveis que contribuíam para diminuir a agitação e amenizar sintomas psicóticos. Contudo, a ECT ocasionava medo e uma experiência traumatizante para o paciente e até mesmo para quem a aplicava. Além disso, foi utilizada por alguns trabalhadores da enfermagem como instrumento punitivo e coercitivo.

Era um aparelho em que colocávamos uma carga elétrica pesada e molhávamos duas bonequinhas com uma água de sal para elas atuarem como transmissoras de eletricidade. Amarrávamos o paciente em uma cama, colocávamos uma borracha na sua boca para ele não morder a lingua, reuníamos duas ou três pessoas para não deixar o paciente se debater, para que não se machucasse. Encostavam-se as duas bonequinhas de uma só vez na fronte do paciente, uma de cada lado, apertava um botão e ele convulsionava na hora. Normalmente quem participava da aplicação do eletrochoque eram o médico e o pessoal da enfermagem. Era uma coisa ruim para o paciente, não era confortável. Tanto que na segunda ou terceira aplicação do eletrochoque, nós tínhamos que pegar o paciente a força para poder fazer a administração. Houve épocas, que funcionários usavam aquilo como castigo, se o paciente perturbasse davam choque. O eletrochoque não era só tratamento, era castigo também. Em alguns casos, o eletrochoque ajudava um pouco, tirava o paciente do delírio, diminuía a agitação, algumas pessoas melhoraram com isso. Mas para outras, esse tratamento não funcionava. Eu acredito que isso cronificava os pacientes, deixava sequelas, tirava a capacidade de reação deles. Há uns oito anos nós tivemos um médico que foi transferido 
para cá, ele tentou implantar de volta o eletrochoque, mas a equipe não aceitou (C1).

A ECT, inicialmente denominada Terapia de Eletrochoque, foi administrada pela primeira vez em Roma, em 1938, por Ugo Cerletti e Lucio Bini. ${ }^{14}$ Por mais que esse método tenha sido muito utilizado desde o seu surgimento, nos anos 60 e 70 sua popularidade declinou. Isso pode ser associado ao advento dos psicofármacos mais efetivos e a crescente movimentação contrária a esse procedimento ocasionada pelo seu uso indevido com o objetivo de punir, controlar ou ameaçar os pacientes. ${ }^{5}$

Apesar da decadência do uso da ECT, nos últimos quinze anos, essa prática voltou a ganhar destaque. ${ }^{5}$ Esse tratamento é considerado efetivo para algumas pessoas que sofrem de transtornos mentais severos, como transtornos depressivos graves, catatonia, mania e certos casos de esquizofrenia. Atualmente, algumas associações psiquiátricas têm se posicionado a favor da ECT, e vários países a inseriram como tratamento de eleição para transtornos mentais. ${ }^{16}$ No Brasil, o Conselho Federal de Medicina (CFM) normatizou esse método por meio da Resolução n. 1.640/2002. ${ }^{17}$

A ECT quando realizada deve ocorrer em ambiente hospitalar, sob anestesia, após a avaliação do estado clínico do paciente. Deve ser obtido antes do procedimento o consentimento do paciente ou de seu responsável, em situações em que ele não tenha condições mentais e/ou etárias para o preenchimento. Ainda, em momentos em que não for possível obter tal documento, o médico poderá aplicar o tratamento, desde que se responsabilize pelo ato. ${ }^{17}$ Nota-se, contudo, que não há um protocolo padrão para a quantidade de aplicações da ECT, de modo que a manutenção dessa terapêutica está a critério da avaliação do paciente após cada sessão. ${ }^{18}$

Em um estudo realizado no Instituto de Psiquiatria da Universidade Federal do Rio de Janeiro, foram comparados os dados de 69 prontuários sobre o uso da ECT de 2005 a 2007, com pesquisas desenvolvidas anteriormente e investigações a respeito do tema em outros países. Os resultados mostraram que todas as aplicações realizadas na instituição estavam de acordo com os critérios válidos e, que embora, a ECT seja polêmica, ela constituiu um bom método para a remissão de sintomas graves. Neste estudo, os autores também reforçaram a importância de estudos direcionados ao estabelecimento do padrão de aplicações necessárias à boa resposta dos pacientes submetidos ao tratamento. ${ }^{18}$

\section{Cubículo ou cela forte}

Os colaboradores narraram a existência de celas fortes, que consistiam em pequenas salas, individuais, fechadas, com portas de material reforçado, que continham uma ou duas aberturas, na parte superior para o profissional observar a pessoa no interior do cubículo e na parte inferior para entregar as refeições. Em todos esses espaços restritivos havia um lugar para que os indivíduos fizessem as eliminações fisiológicas e se deitassem.

As pessoas eram encaminhadas para os cubículos quando estavam muito agitadas ou agressivas. Todavia, esses recintos também serviram para que alguns funcionários os usassem como um castigo para os pacientes. Não existia um tempo de permanência estabelecido para a reclusão, podia ser de 2 a 3 horas, até vários dias. Conforme relato do colaborador C3, no hospital campo deste estudo a desativação dos cubículos se deu no final de 1980.

Havia os cubículos onde os pacientes eram jogados. Era uma cela. Quando o paciente ficava agitado, era colocado nesse lugar, qualquer coisinha era cubículo. Lá tinha somente uma patente e um colchão de capim no chão, quando tinha. Era escuro, tinha uma janelinha lá em cima. A comida era jogada por uma portinhola (C3).

Os cubículos eram salas fechadas, de mais ou menos $3 m^{2}$, com uma abertura embaixo na porta para dar a alimentação e uma em cima para observarmos o paciente, tinham um vaso sanitário daqueles de chão e um colchão. Para aplicar a medicação injetável, era preciso entrar mais de um auxiliar de enfermagem e se necessário conter o paciente. Para o banho, o paciente era retirado de lá e depois a enfermagem o colocava lá novamente. A porta era bem reforçada para que ele não pudesse arrebentá-la. Parecia um isolamento de solitária. O paciente muito agitado, que agredia outro paciente ou um funcionário, era encaminhado para lá. Não era um castigo, era um isolamento porque ele não tinha condição de ficar na unidade. Geralmente ele não queria ir para lá, tinha medo, ninguém quer ficar fechado, ia à força. Lá ele ficava isolado por sete dias, às vezes, até mais tempo. A intenção era que ele refletisse, se acalmasse (C4).

Em uma pesquisa realizada no Paraná, com famílias que vivenciam o tratamento da pessoa com transtorno mental, um sujeito verbalizou ter tido a experiência de ficar isolado em um cubículo após desentendimento com outro paciente. Ele mencionou que no período de reclusão não era possível alimentar-se e nem ingerir líquidos. A pessoa perdia a noção espacial e temporal e, ao 
ser retirada daquele local, apresentava-se confusa e desorientada. ${ }^{19}$

A Portaria MS n. 224/1992, na perspectiva de viabilizar a humanização da assistência e a preservação da cidadania da pessoa com transtorno mental nos hospitais psiquiátricos, entre outras determinações, proibiu a existência de celas fortes..$^{12-13}$ A Portaria GM n. 251/2002, mantém a proibição desses espaços restritivos, ${ }^{12}$ prática que propicia exclusão e sofrimento para o paciente internado.

\section{Praxiterapia}

Outra modalidade de tratamento narrada pelos colaboradores foi a praxiterapia em que os internos desempenhavam tarefas laborais, como a horticultura e criação de galináceos e suínos, sob a orientação dos funcionários. Essa prática possibilitava uma ocupação aos pacientes, conferindo uma ação terapêutica. Entretanto, foi muito empregada até a década de 1980 como um instrumento de exploração de trabalho.

A horta terminou em 2000 mais ou menos, mas nessa época ela já estava bem reduzida e o funcionamento era diferente. Quando era ativa mesmo, na década de 1980, ela era enorme. Os pacientes eram levados para a horta, lá eles carpiam, plantavam, regavam, colhiam. Eu achava que era bom porque era uma forma deles se ocuparem, mas por outro lado penso que era um esforço muito grande para eles, pois muitas vezes as pessoas que comandavam aquelas atividades se aproveitavam deles. $O$ [nome do funcionário], que hoje já se aposentou, agredia pacientes, chicoteava. Ele fazia o paciente trabalhar mesmo (C4).

A praxiterapia consistia no uso terapêutico do trabalho. No Brasil, ela foi oficializada em 1890 por meio do Decreto n. 206-A, que aprovou instruções para a assistência médica legal de alienados. Nota-se que esse aparato se destinava aos "alienados indigentes", capazes de trabalhar na agricultura e indústrias nas colônias. Estes locais foram criados principalmente para solucionar os problemas de superlotação de pobres e miseráveis no Hospício Nacional de Alienados. No entanto, havia também o interesse terapêutico em proporcionar tratamento baseado no trabalho, especialmente em atividades de agropecuária e produção artesanal. $^{2}$

Ainda, no interior da instituição asilar havia um contingente de pessoas com condições de desempenhar atividades que estavam sem ocupação. Assim, em 1903 Hermann Simon, utilizou a força de trabalho de pacientes para a construção de um hospital e registrou a melhoria que essa atividade produziu nos pacientes, instituindo a terapêutica ocupacional. ${ }^{20}$

O uso de atividades laborais como forma de terapia foi uma das mais importantes aplicações de tratamento moral. Inúmeras instituições psiquiátricas do tipo colônias de alienados foram originadas em todo o Brasil. A ideia era que pessoas com transtornos mentais pudessem trabalhar nesses espaços, sobretudo na lavoura, pois o trabalho as recuperaria. ${ }^{21}$

Em um estudo realizado acerca das terapias utilizadas em um hospital psiquiátrico em Santa Catarina entre os anos de 1941 e 1961, a praxiterapia também foi mencionada. Tratava-se de um recurso que visava ocupar integralmente o tempo dos portadores de transtorno mental. O trabalho era visualizado como uma forma de introjetar na pessoa a atenção, a coordenação dos atos, a obediência, entre outras qualidades. Os pacientes desenvolviam atividades que eram permitidas tanto pelos seus graus de periculosidade, como pelas suas condições físicas e aptidões individuais em vários setores da instituição, como serraria, olaria, carpintaria, suinocultura, agricultura, capinação, lavanderia, costura, cozinha e limpeza. ${ }^{22}$

Apesar dos aspectos positivos da praxiterapia, a fala do colaborador C4 mostrou o mau emprego dessa técnica até a década de 1980. Ela era uma condição imposta para os pacientes, que visava à produtividade. Pessoas chegavam a ser açoitadas, assemelhando-se a escravos. Se por um lado essa prática surgiu para exercer ação terapêutica mediante a ocupação e o contato com a natureza, a exemplo de outras terapias citadas neste estudo ou em outras pesquisas, ela trouxe resultados mais iatrogênicos do que curativos e de reabilitação pelo seu mau uso tanto por profissionais da enfermagem, quanto por médicos e donos de hospitais.

\section{Lençol de contenção e camisa de força}

Os colaboradores narraram o uso do lençol de contenção, também denominado de jacaré, até 1990. Ao discorrerem sobre esta técnica, simultaneamente, intercalavam informações a respeito da camisa de força. Para eles o aspecto positivo do lençol de contenção era ser rapidamente colocado, todavia chegava a machucar os pacientes. A camisa de força ou colete conferia grande risco de queda. Essas técnicas foram adotadas ou tiveram seu uso intensificado a partir da extinção dos cubículos. 
O colete era colocado em pacientes que se autoagrediam, eles ficavam apenas com os braços amarrados, conseguiam andar, só que era perigoso porque podia cair, a enfermagem precisava ficar atenta. Já o lençol de contenção continha a pessoa na cama. O paciente ficava deitado, vestíamos nele uma lona com braçadeiras de couro e fivela que prendiam as pernas e os braços no leito. Colocávamos ali uma proteção para não garrotear os membros. A pessoa não podia ficar contida dessa forma por muito tempo, para não machucá-la, logo que o médico a sedava, o lençol de contenção era retirado. Quando um paciente mesmo após a medicação não dormia, conversávamos com ele, se estivesse calmo, removíamos a contenção. Mas lembro que houve muitos casos de soltarmos o indivíduo e imediatamente termos que contê-lo novamente. Era soltar e ele nos agredir (C6).

A camisa de força ou colete de força foi introduzida por Pinel, no século XIX, e substituiu as correntes, algemas e celas fortes utilizadas nos manicômios. Esse recurso foi considerado uma forma de contenção física menos dolorosa, mais transitória e menos excludente que os dispositivos que existiam naquela época. ${ }^{23}$

Durante mais de 50 anos a camisa de força foi utilizada no tratamento psiquiátrico. Ela foi amplamente empregada no Brasil. Era confeccionada com tecido do tipo lona resistente, possuía mangas muito compridas e fechadas para serem amarradas nas costas. O paciente permanecia amarrado, imobilizado e inofensivo. ${ }^{10}$ Ao imobilizar somente os membros superiores, a camisa de força permitia que a pessoa não ficasse restrita ao leito, no entanto, aumentava o risco de quedas e ferimentos, especialmente no rosto, uma vez que prejudicava o equilíbrio e diminuía a possibilidade de o paciente ao cair se proteger com os braços. ${ }^{24-25}$

Tais apontamentos condizem com as falas dos colaboradores e também podem ser observados nos resultados de uma pesquisa realizada com profissionais de enfermagem de um hospital psiquiátrico que teve como objeto de estudo a contenção física. Os participantes mencionaram que quando a camisa de força era utilizada, comumente acontecia de o paciente cair e se machucar, sendo necessário por vezes fazer sutura. Ressaltaram que esse tipo de contenção não evitava por completo que a pessoa agredisse os outros, pois como os membros inferiores ficavam livres, eles poderiam ser usados. ${ }^{24-25}$

O lençol de contenção era confeccionado de lona grossa e tinha correias de couro, portanto, oferecia um contato desagradável ao indivíduo contido e transmitia uma mensagem de medo e agressividade, revelada por pacientes ao apelidá-lo de "arreio". Na pesquisa referida anteriormente, os sujeitos fizeram colocações que vêm ao encontro do que foi exposto pelos colaboradores deste estudo. Contaram que o lençol de contenção tinha uma estrutura física muito rudimentar, pesava bastante sobre o paciente, o incomodava e em muitas vezes lhe causava ferimentos. Não obstante, esse tipo de contenção era uma técnica boa e fácil, pois, segundo os sujeitos, era realizada de forma rápida. ${ }^{24-25}$

\section{Contenção no leito com faixas de tecido de algodão}

A contenção física no leito por faixas de tecido de algodão foi outra técnica citada pelos colaboradores, e que inclusive perdura até os dias atuais. Contudo, devido às mudanças decorrentes da reforma psiquiátrica, eles explicitaram que ela não é utilizada como primeira escolha. Ela é aplicada para a proteção do paciente, de outros indivíduos e para a pessoa contida ter um tempo para pensar em seus atos. Esse procedimento é de indicação médica. Alguns cuidados durante a contenção física foram referidos pelos colaboradores, tais como a realização correta da técnica, o monitoramento constante do indivíduo contido, a verificação dos dados vitais e das condições circulatórias e a avaliação da supervisão de enfermagem.

Atualmente a contenção mecânica é realizada com faixas para assegurar a integridade física do paciente, para proteção do outro e também em casos em que o usuário está muito angustiado e não consegue parar e ter um tempo para ele. Todas as contenções são realizadas com indicação médica. Quando há uma situação de agressividade, que o paciente está agitado, batendo, quebrando, a enfermagem faz a técnica, mas imediatamente o médico é avisado para prescrever. Daí a supervisão de enfermagem vai lá, vê todos os cuidados, como é que está a circulação do paciente, o estado geral dele. O tempo de contenção é no máximo de três horas. Mas há paciente que às vezes está muito agitado, podendo este período ser ultrapassado com monitoramento e acompanhamento constante (C2).

A contenção tem que ser terapêutica. Alguns cuidados são importantes, como conter o paciente o mais próximo do posto de enfermagem, não deixá-lo sozinho, olhá-lo a todo o momento, verificar sinais vitais, observar se ele está bem, se está tendo resposta e se continuar muito agitado chamar o médico para ver se há necessidade de uma medicação; não dar líquidos ou alimentos e cuidar para que outros pacientes também não deem (C1). 
Como medida terapêutica, a contenção física no leito com faixas de tecido de algodão deve ser realizada somente como último recurso, depois de esgotadas todas as tentativas de acalmar o paciente pela abordagem verbal. ${ }^{26}$ Esta prática envolve o uso de dispositivos mecânicos ou manuais para limitar os movimentos do paciente, para proteger a ele próprio ou os demais. ${ }^{14}$

Tal situação requer que esse tema seja objeto de discussão e normatização pela categoria profissional, além de que ela seja realizada de modo terapêutico e não com descaso ou como forma de punição a alguém que se encontra em momento de sofrimento, portanto, fragilizado por sua condição.

Estudo $^{25}$ que objetivou investigar como ocorre a contenção física revelou que os sujeitos mencionaram o uso desse instrumento como terapêutico, devendo ser utilizado em situações de agitação psicomotora, agressividade e quando há necessidade de estabelecer limites. Para eles, o uso da contenção física no leito com faixas de tecido de algodão propicia, na maioria das vezes, resultados positivos, como a diminuição da ansiedade e a liberação dos sentimentos de raiva. Além disso, houve relatos que em algumas situações essa técnica acaba por dispensar o uso de medicamentos e confere tempo para a pessoa contida repensar suas atitudes, sua vida e até externar sentimentos não mencionados em outros momentos.

Outra preocupação refere-se ao uso de faixas apropriadas para a contenção e aos cuidados de enfermagem, como vigilância contínua do indivíduo contido, conforto, proteção, avaliação na presença de comorbidades clínicas e obstétricas, controle de sinais vitais e perfusão sanguínea e avaliação do enfermeiro. ${ }^{25}$

\section{CONCLUSÕES}

As narrativas dos colaboradores contribuíram para recuperar a memória da assistência ao portador de transtorno mental praticada dentro de hospitais psiquiátricos no recorte temporal (1960 a 2000). Esse histórico facilita o entendimento do presente, nos remete à discussão de saúde mental, seus atores e cenários, as influências sofridas ao longo do tempo e seus impactos e implicações na sociedade.

As histórias externadas neste estudo evidenciaram que os tratamentos adotados nas instituições em que os colaboradores trabalharam vêm ao encontro daqueles utilizados nos hospitais psiquiátricos dos grandes centros brasileiros.
Foram mencionadas as terapias biológicas: os psicofármacos, o choque cardiazólico, a insulinoterapia e a eletroconvulsoterapia. Destes, o choque cardiazólico e a insulinoterapia caíram em desuso, e a eletroconvulsoterapia é empregada por alguns centros de pesquisa e tratamento de transtornos mentais. As terapias de ideologia moral, como as atividades laborais, e as de restrição física, representadas pela cela forte, o lençol de contenção, a camisa de força e a contenção no leito por faixas de tecido de algodão foram mencionadas pelos colaboradores sendo que as celas fortes têm proibição em legislação federal.

É importante ressaltar que alguns tipos de tratamentos que no presente são considerados incipientes e em desuso, eram os disponíveis durante o recorte temporal do estudo, de 1960 a 2000, no entanto, mesmo sendo originados para exercerem uma ação terapêutica, por vezes, foram utilizados de forma desumana e coercitiva.

\section{REFERÊNCIAS}

1. Stockinger RC. Reforma psiquiátrica brasileira: perspectivas humanistas e existenciais. Rio de Janeiro (RJ): Vozes; 2007.

2. Canabrava DS, Souza TS, Fogaça MM, Guimarães AN, Borille DC, Villela JC, et al. Tratamento em saúde mental: estudo documental da legislação federal do surgimento do Brasil até 1934. Rev Eletr Enferm [online]. 2010; 12(1) [acesso 2011 Jan 05]. Disponível em: http://www.fen.ufg.br/ fen_revista/v12/n1/pdf/v12n1a21.pdf

3. Peres MAA, Barreira IA. Desenvolvimento da assistência médica e de enfermagem aos doentes mentais no Brasil: os discursos fundadores do hospício. Texto Contexto Enferm. 2009 Out-Dez; 18(4):635-42.

4. Andrade RLP, Pedrão LJ. Algumas considerações sobre a utilização de modalidades terapêuticas não tradicionais pelo enfermeiro na assistência de enfermagem psiquiátrica. Rev Latino-am Enfermagem. 2005 Set-Out; 13(5):737-42.

5. Silva MLB, Caldas MT. Revisitando a técnica de eletroconvulsoterapia no contexto da reforma psiquiátrica brasileira. Psicol Cienc Prof. 2008 AbrJun;28(2):344-61.

6. Jorge MSB, Silva WV, Oliveira FB, organizadores. Saúde mental: da prática psiquiátrica asilar ao terceiro milênio. São Paulo (SP): Lemos Editorial; 2000.

7. Meihy JCSB, Holanda F. História oral: como fazer como pensar. São Paulo (SP): Contexto; 2007.

8. Ministério da Saúde (BR), Conselho Nacional de Saúde, Comissão Nacional de Ética em Pesquisa. Resolução N. 196 de 10 de outubro de 1996: diretrizes 
e normas regulamentadoras de pesquisa envolvendo seres humanos. Brasília (DF): MS; 1996.

9. Minayo MCS. O desafio do conhecimento: pesquisa qualitativa em saúde. São Paulo (SP): Hucitec; 2004.

10. Ministério da Saúde (BR), Secretaria-Executiva, Subsecretaria de Assuntos Administrativos, Coordenação-Geral de Documentação e Informação, Centro Cultural da Saúde. Memória da Loucura: apostila de monitoria. Brasília (DF): MS; 2005.

11. Borenstein MS, Pereira VP, Ribas DL, Ribeiro AAA. Historicizando a enfermagem e os pacientes em um hospital psiquiátrico. Rev Bras Enferm. 2003 MarAbr; 56(2):201-5.

12. Ministério da Saúde (BR), Secretaria-Executiva, Secretaria de Atenção à Saúde. Legislação em Saúde Mental: 1990-2004. 5a ed. Brasília (DF): MS; 2004.

13. Guimarães AN, Fogaça MM, Borba LO, Paes MR, Larocca LM, Maftum MA. O tratamento ao portador de transtorno mental: um diálogo com a legislação federal brasileira (1935-2001). Texto Contexto Enferm. 2010 Abr-Jun; 19(20):274-82.

14. Sadock BJ, Sadock VA. Compêndio de psiquiatria: ciência do comportamento e psiquiatria clínica. $9^{\mathrm{a}}$ ed. Porto Alegre (RS): Artmed; 2007.

15. Sabbatini RME. A história da terapia por choque em psiquiatria. Rev Cérebro Mente [online]. 1997;4(4) [acesso 2011 Jan 05]. Disponível em: http:/ /www. cerebromente.org.br/n04/historia/shock.htm

16. Salleh MA, Papakostas I, Zervas I, Christodoulou G. Eletroconvulsoterapia: critérios e recomendações da Associação Mundial de Psiquiatria. Rev Psiquiatr Clín. 2006 Set-Out; 33(5):262-7.

17. Brasil. Resolução N. 1.640, de 10 de julho de 2002. Dispõe sobre a eletroconvulsoerapia e dá outras providências. Diário Oficial da União, 9 Ago 2002. Seção 1.
18. Pastore DL, Bruno LM, Nardi AE, Dias AG. O uso da eletroconvulsoterapia no Instituto de Psiquiatria da Universidade Federal do Rio de Janeiro no período de 2005 a 2007. Rev Psiquiatr Rio Gd Sul. 2008 SetDez; 30(3):175-81.

19. Borba LO. Vivência familiar de tratamento da pessoa com transtorno mental em face da reforma psiquiátrica [dissertação]. Curitiba (PR): Universidade Federal do Paraná. Programa de PósGraduação em Enfermagem; 2010.

20. Birman J, Costa JF. Organização de instituições para uma psiquiatria comunitária. In. Amarante $\mathrm{P}$, organizador. Psiquiatria social e reforma psiquiátrica. Rio de Janeiro: Fiocruz; 1994. p.41-53.

21. Amarante P. Rumo ao fim dos manicômios. Mente Cérebro. 2006 Set; 164(9):30-5.

22. Borenstein MS, Padilha MICS, Ribeiro AAA, Pereira VP, Ribas DL, Costa E. Terapias utilizadas no Hospital Colônia Sant' Ana: berço da psiquiatria catarinense (1941-1960). Rev Bras Enferm. 2007 NovDez; 60(6):665-9.

23. Pessoti I. O século dos manicômios. São Paulo (SP): Editora 34; 1996.

24. Paes MR, Borba LO, Maftum MA. Contenção física de pessoas com transtorno mental: percepções da equipe de enfermagem. Cienc Cuid Saude. 2011 Abr-Jun; 10(2):240-7.

25. Paes MR, Borba LO, Brusamarello T, Guimarães AN, Maftum MA. Contenção física em hospital psiquiátrico e a prática da enfermagem. Rev Enferm UERJ. 2009 Out-Dez; 17(4):479-84.

26. Estelmhsts P, Brusamarello T, Borille D, Maftum MA. Emergências em saúde mental: prática da equipe de enfermagem durante o período de internação. Rev Enferm UERJ. 2008 Jul-Set; 16(3):399-403. 